\title{
Fibre Synergy in Concrete Matrix
}

\author{
J. Vikram \\ Associate Professor, Department of Civil Engineering, METS School of Engineering, Thrissur, Kerala, India
}

\begin{abstract}
Many researches were made to evaluate the performance of fibre addition to increase the performance of concrete. It a well know act that the toughness index of concrete increases due to fibre addition. Limited concentrations were given to evaluate the synergy between fibres. In case of hybrid fibre addition there is a noticeable effect in the performance of concrete is generated due to the effect of fibre synergy. In this study, a carefully designed slag based concrete mix were developed and it is reinforced with different type of fibre combination varying type of fibre and dosage. The synergy is calculated by the post crack performance of the concrete mixes. The result shows longer fibres with maximum dosage of polypropylene shows a better synergy than other mixes and all fibre concrete shows a better synergy than single fibre addition.
\end{abstract}

Keywords: composite, fibre, slag, steel/polypropylene, synergy

\section{Introduction}

In general, fibre reinforcement deals with only single type of fibre addition to strengthen the concrete matrix [1]. The influence of single fibre addition might not show any significant effects on the post performance of the concrete when compared to two types of fibre addition [2]. The present study focused on the synergistic interaction of composite fibre reinforcement in high strength concrete matrix. A carefully designed slag based concrete based on material packing density is arrived with low cement content in the total binder content. Crimped polypropylene fibre and hooked steel fibres were used as composites in the concrete mixes. The synergy of composite fibre reinforced concrete is evaluated from the post crack behavior of the concrete specimen.

\section{Mix Proportions}

The mix proportions were arrived based on the three phase particle interaction based on packing density of the concrete material and shown in 1 . Cement \& Slag in 50\% quantity is used as binder. River sand as fine aggregate and $12.5 \mathrm{~mm}$ and $20 \mathrm{~mm}$ coarse aggregates are used. High range water reducing plasticizer $1 \%$ by volume of binder and $0.3 \mathrm{w} / \mathrm{c}$ ratio were adopted in this study.

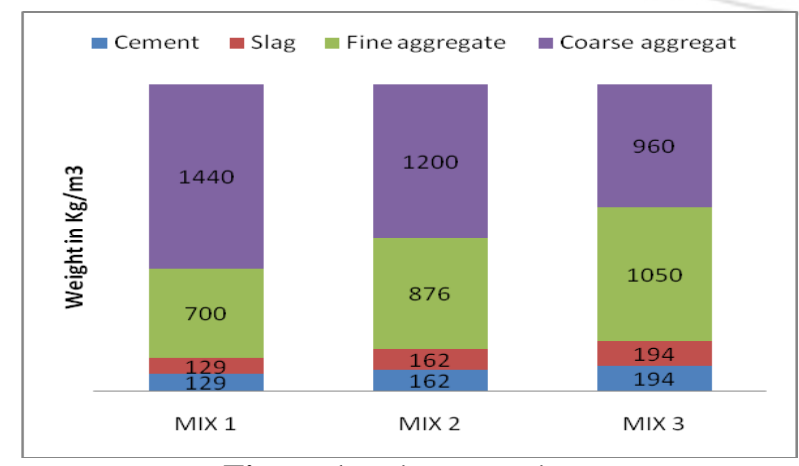

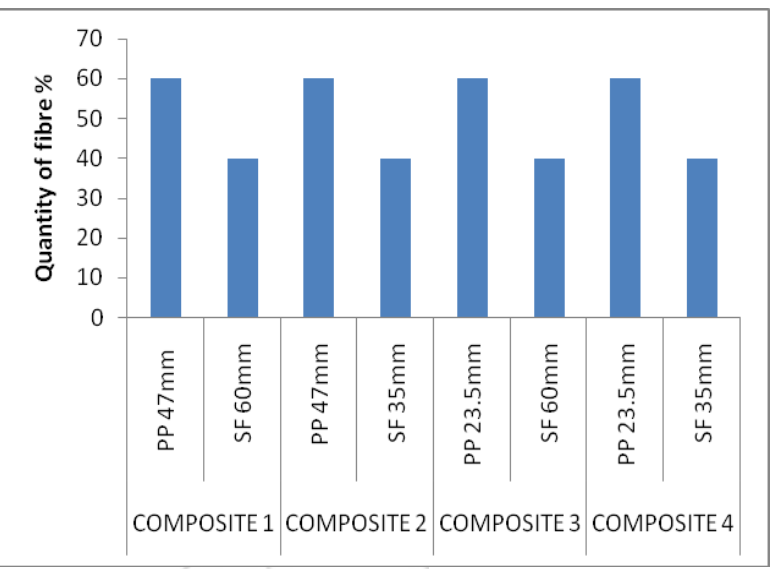

*PP - Polypropylene fibre \& SF - Steel fibre

Figure 2: Different combinations of fibre used to develop a composite fibre to be added to the concrete.

12 mixes were arrived from three types of concrete mix with four combination of composite fibre. Fibre dosage is kept constant as $60 \%$ of polypropylene fibre (PP) and $40 \%$ of steel fibre (SF).

\section{Evaluation of Post Crack Toughness}

Prism of size 500x100x100 mm were casted and tested under three point loading condition in flexural testing machine. The toughness value is computed by tabulating the load - deflection plot using Graph version 4. The post crack region denotes the performance of the concrete after failure.

Plain concrete fails suddenly without exhibiting post crack performance. All the other composite mixes take load even after failure. 3 shows the post crack toughness values which evidently show mix HYF2 (47mm PP \& 60mm SF) has a higher value in the post crack region.

Figure 1: Mix proportions 


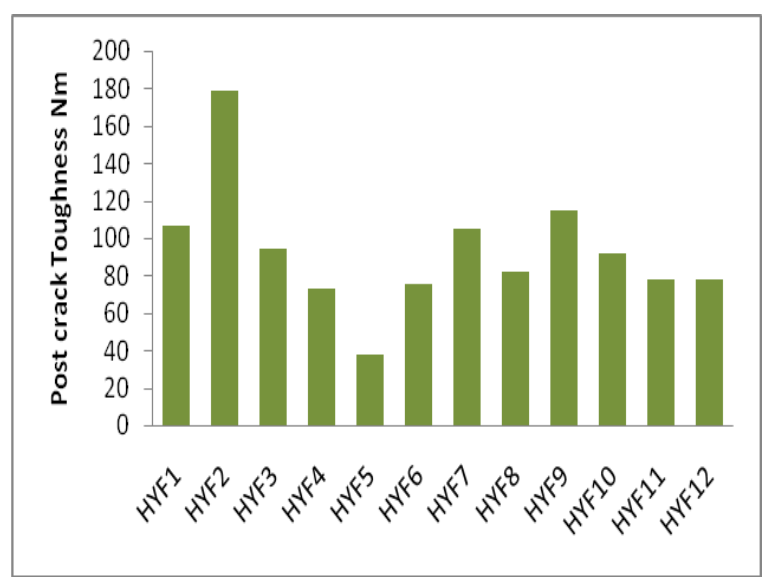

Figure 3: Post crack toughness of composite mixes

\section{Fibre Synergy}

The performance of single fibre replaced with two thereby increasing the performance is called as synergy. From the post crack toughness, the synergy value is computed (1) and shown in 4. If these values are positive then a positve synergy is developed.

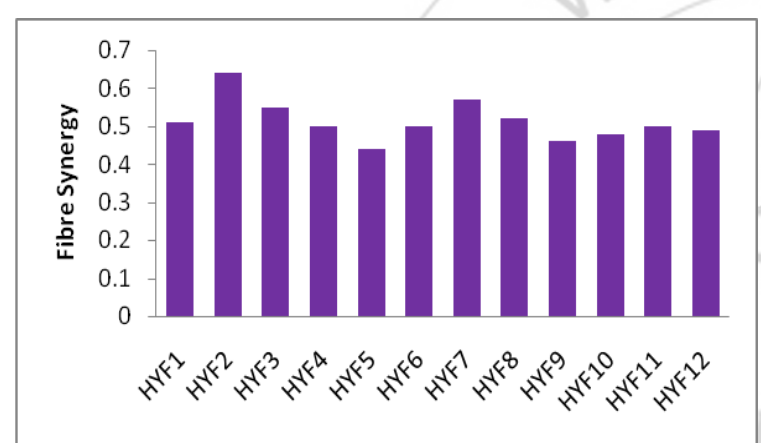

Figure 4: Synergy of composite fibre

It is aslo found that mis HYF2 recordes a comapritively higher value.

\section{Conclusion}

Experiments were conducted under laboratory condition. From the test results, it is found that longer fibre combination ( $47 \mathrm{~mm}$ PP \& $60 \mathrm{~mm} \mathrm{SF})$ in mix 1 contributing to HYF2 combination shows better performance in the post crack region which is also justified by its fibre synergy. Application of longer fibre combination could be a solution for better crack bridging effect.

\section{References}

[1] N. Banthia, F. Majdzadeh, J.Wu. V. Bindiganavile: Fiber synergy in Hybrid Fiber Reinforced Concrete (HyFRC) in flexure and direct shear, Cement \& Concrete Composites 48 (2014) 91-97

[2] Banthia N, Soleimani SM: Flexural response of hybrid fibre-reinforced cementitious composites, ACI Materials Journal, 102(2005) 382-9. 